\title{
Management of acute coronary syndrome in emergency departments: a cross sectional multicenter study (Tunisia)
}

\author{
Asma Sriha Belguith ${ }^{1 *}$, Kaouthar Beltaief ${ }^{2}$, Mohamed Amine Msolli², Wahid Bouida², Hela Abroug', \\ Manel Ben Fredj ${ }^{1}$, Imen Zemni', Mohamed Habib Grissa'2, Hamdi Boubaker ${ }^{2}$, ESCor Investigators group, \\ Mohamed Hsairi ${ }^{3}$, Samir Nouira ${ }^{2}$ and On behalf of the ESCorT Investigators group
}

\begin{abstract}
Background: We aimed to describe diagnosed acute coronary syndrome (ACS) and its care management and outcomes in emergency departments (EDs) and to determine related cardiovascular risk factors (CVRFs).

Methods: We conducted a cross sectional multicenter study that included 1173 adults admitted to EDs for acute chest pain (ACP) in 2015 at 14 sites in Tunisia. Data included patients' baseline characteristics, diagnosis, treatment and output.

Results: ACS represented $49.7 \%$ of non-traumatic chest pain [95\% Cl: 46.7-52.6]; $74.2 \%$ of ACS cases were unstable angina/non-ST-segment-elevation myocardial infarction (UA/NSTEMI). Males represented $67.4 \%$ of patients with ACS $(p<0.001)$. The median age was 60 years (IQR 52-70). Emergency medical service transportation was used in 11.9\% of cases. The median duration between chest pain onset and ED arrival was two hours (Inter quartile ranges (IQR) 2-4 h). The age-standardized prevalence rate was 69.9/100,000 PY; the rate was 96.24 in men and 43.7 in women. In the multivariable analysis, CVRFs related to ST segment elevation myocardial infarction were age correlated to sex and active smoking. CVRFs related to UA/NSTEMI were age correlated to sex, familial and personal vascular history and type 2 diabetes. We reported 27 cases of major adverse cardiovascular events (20.0\%) in patients with STEMI and 36 in patients with UA/NSTEMI (9.1\%).

Conclusion: Half of the patients consulting EDs with ACP had ACS. Emergency medical service transportation calls were rare. Management delays were acceptable. The risk of developing an UA/NSTEMI was equal to the number of CVRFs +1 . To improve patient outcomes, it is necessary to increase adherence to international management guidelines.
\end{abstract}

Keywords: Acute coronary syndrome, Epidemiology, Cardiovascular risk factors, Management, Tunisia

\section{Background}

\section{Background/rationale}

The majority of cardiovascular disease (CVD) deaths occurred in developing countries in 2015 [1], with increasing trends, despite improvements in preventive actions and management $[2,3]$. Therefore, acute chest pain $(\mathrm{ACP})$ is a major emergency.

* Correspondence: belguith_asma@yahoo.fr

${ }^{1}$ Epidemiology and Preventive Medicine Department, University Hospital of

Monastir, Monastir, Tunisia

Full list of author information is available at the end of the article
Physicians must quickly recognize highly suspected acute coronary syndrome (ACS) [4-8]. The prevalence of ACS varies within regions in Tunisia, according to the level of urbanization and lifestyle habits. Data on ACS epidemiology and management are rare; therefore, studying ACS in Tunisian emergency departments is necessary.

\section{Objectives}

This study aimed to describe the ACS prevalence and management in Tunisian emergency departments (EDs), to quantify the relationship between cardiovascular risk 
factors (CVRFS) and ACS, and to determine Major Adverse Cardiac Events (MACE) related to ACS.

\section{Methods \\ Study Design}

We conducted a multicenter cross-sectional study that included fourteen EDs.

Data were prospectively collected from February to September 2015.

\section{Setting}

This study included eight university emergency departments (Monastir, Mahdia, Sahloul, Farhat Hached, Kairouan, Rabta, and Ben Arous) and seven regional emergency departments (Mahres, Djebeniana, Jemmal, Ksar_Hellal, Nefidha, Moknine, and ElKram). Tunisia is a Northwest African state covering 165,000 square kilometers. Tunisia's population was estimated to be more than 11 million in 2014. In 2009, there were 12 physicians and 33 nurses per 10,000 inhabitants (inh).

\section{Participants}

We included patients at least 30 years old admitted to the ED for nontraumatic chest pain and who signed an informed consent form. We did not include patients with obvious pulmonary disease or with traumatic chest pain or patients who were unable to give consent (e.g., cognitive impairment) or who were participating in another trial. Deaths at home following suspected ACS were not included. Patients with nontraumatic chest pain and who had diseases other than ACS were considered as the population control.

\section{Variables}

Data included variables related to socio-demographic population characteristics (age, sex, and origin), timeline (chest pain onset according to patient description, ED arrival, ACS treatment start time and length of stay), history (vascular family history, vascular personal history, coronary personal history, revascularization, peripheral arterial history, and stroke) and conventional CVRFs (treated HTA, treated type 2 diabetes, active smoking, and treated dyslipidemia). We also collected information about current medications (beta-blockers, converting enzyme inhibitors (ACE inhibitors), oral antidiabetics (OAD), statins and aspirin). ACS was defined according to electrocardiographic changes, serial increases in necrosis cardiac biomarkers, or documented coronary artery disease. Patients were diagnosed with ST segment elevation myocardial infarction (STEMI) or unstable angina pectoris/negative ST segment elevation myocardial infarction or (UA/NSTEMI) using standardized criteria. Conventional classification of CVRFs was used [9]. The emergency output mode were exit at home after emergency supervision or transfer to other service (cardiology). Major adverse cardiac events (MACE), were also recorded, as these are the most commonly used composite endpoints in cardiovascular research and were defined in our study as effectiveness outcomes, which included death, major arrhythmia, major conduction disorders and acute pulmonary edema.

\section{Data collection/measurement}

The data register was collected at hospital discharge, in compliance with international guidelines and national laws and regulations. All necessary regulatory submissions were performed in accordance with local regulations, including local data protection regulations. Crude prevalence rates (CPRs) of ACS were calculated based on the Tunisian National Institute of Statistics and expressed in 100,000 inh [10]. The age-standardized prevalence rate (ASR) per 100,000 person-years (PY) was calculated among the world standard population according to the WHO 2013 report.

\section{Bias}

To minimize information bias, we performed training with participating physicians and their staff. Trained physicians and staff in each emergency department verified the data collected and sought to minimize missing data. Authorized secretaries collected and verified data with Statistical Package for Social Science (SPSS) software version 21.0.

\section{Study size}

According to an exploratory study [8], a diagnosis of ACS was confirmed in $38 \%$ of chest pain unit patients managed in a Tunisia ED. To have an accuracy of $3 \%$, we had to include at least 1005 patients with nontraumatic acute chest pain. Considering a missing data rate of $10 \%$ according to local experience, the target number of subjects to include was 1105 .

\section{Quantitative variables}

Age groupings were chosen as young adult (30-40 years), adult (40-60 years) and elderly (> 60 years). Age correlated with sex was defined as men over 55 and women over 65. Medians and inter quartile ranges (IQRs) are used to describe durations.

\section{Statistical methods}

Data were analyzed with SPSS version 21.0. Descriptive, univariate and multivariable statistical analyses were performed.

Categorical variables (age group, sex, cause of chest pain and CVRFs) are presented as counts and percentages. Significant risk factors related to ACS in the univariate analysis with $\mathrm{p}$ value of 0.20 were included in 
the multivariable logistic regression model. The included variables in the first model were age correlated with sex, vascular family history, vascular personal history, coronary personal history, treated hypertension, treated type 2 diabetes, active smoking, treated dyslipidemia and obesity. In the second model, we included the sum of CVRFs as an ordinal variable. The results are expressed as odds ratios (ORs) with 95\% confidence intervals (95\% CIs). Linear interpolations and Spearman's rho coefficient were determined to assess the relationship between the number of CVRFS and the risk of ACS.

\section{Results}

\section{Participants}

We included 1173 admissions for ACP; of these, 566 were diagnosed as ACS (49.7\%; 95\% CI: 46.7- 52.6\%). UA/NSTEMI represented $74.2 \%$ of all ACS cases.Four patients were excluded from the analysis because they were less than 30 years of age.

\section{Descriptive data}

Males represented $67.4 \%$ of patients with ACS $(p<0.001)$. The sex ratio (Men/Women) was 3.55 among patients diagnosed with STEMI (Table 1). The median age of ACS patients at admission was 60 years (IQR 52-70); the median age was 63 years for women (IQR 53-74) and 59

Table 1 Chest pain characteristics $(n=1173)$ : FebruarySeptember; 2015

\begin{tabular}{|c|c|c|c|c|}
\hline & $\mathrm{N}$ & $\%$ & $\begin{array}{l}\text { Age (years) } \\
\text { Median (QR) }\end{array}$ & Sex-ratio \\
\hline All chest pain & 1173 & 100 & $58(49-68)$ & 1.81 \\
\hline \multicolumn{5}{|l|}{ Cause of chest pain } \\
\hline Cardiac $n(\%)$ & 589 & 51.71 & & \\
\hline Acute coronary syndrome & 566 & 49.69 & $60(52-70)$ & 2.07 \\
\hline STEMI & 146 & & $60(52-68)$ & 3.55 \\
\hline UA/NSTEMI & 420 & & $60(52-70)$ & 1.75 \\
\hline Aortic dissection & 2 & 0.18 & 72 & 2 \\
\hline Pulmonary embolism & 7 & 0.61 & $75(34-80)$ & 0.4 \\
\hline Pericarditis/Tamponade & 14 & 1.23 & $52(39-67.5)$ & 2.5 \\
\hline Non-cardiac causes n (\%) & 550 & 48.29 & & \\
\hline Pneumothorax & 9 & 0.79 & $34(31-46)$ & 8 \\
\hline Pleurisy & 15 & 1.32 & $61(55-78)$ & 1.5 \\
\hline Osteochondritis & 35 & 3.07 & $62(58-75)$ & 1.69 \\
\hline Neuralgia of intercostal nerve & 149 & 13.08 & $53(45-63.75)$ & 2.36 \\
\hline Digestive pathology & 45 & 3.95 & $59(46-73.5)$ & 1.05 \\
\hline Psycho-pathologic disease & 106 & 9.31 & $51(39.75-60)$ & 1.08 \\
\hline Irrelevant cause & 191 & 16.77 & $58(48-71)$ & 1.58 \\
\hline
\end{tabular}

QR quartile range, UA/NSTEMI unstable angina/non-ST-segment-elevation myocardial infarction, STEMI ST segment elevation myocardial infarction Legend: The half of patient consulting emergency departments for chest pain were diagnosed as acute coronary syndrome especially UA/NSTEMI years (IQR 52-67) for men ( $p=0.003)$. According to the CVRFs, the median age at ACS was 54 years (IQR 45-61) among active smokers and 73 years (IQR 67-84) in patients treated for hypertension (Fig 1).

\section{Outcome data}

Emergency medical service transportation was used in $11.9 \%$ of cases then $88.1 \%$ of patients reached the hospital using their own means of transport. Two hours was the median duration between chest pain onset and ED arrival (IQR: 2-4 h). Pre-hospital delays, starting treatment delays and length of stay were significantly shorter in men, in STEMI cases and among younger patients (Fig 2). Transfer to the Cardiology Intensive Care Unit was performed in $73.9 \%$ and $38.3 \%$ of STEMI and UA/NSTEMI cases, respectively (Table 2). Forty-three percent of NSTEMI patients were discharged home after surveillance at emergency departments.

\section{Major Adverse Cardiac Events (MACE)}

We reported 27 cases of MACE (20.0\%) in patients with STEMI and 36 in patients with UA/NSTEMI (9.1\%), representing $11.8 \%$ in all ACS cases. Seven cases of sudden cardiac arrest were reported (three cases among STEMI patients and four among UA/NSTEMI patients); five resulted in premature death $(71.4 \%)$ (Table 2).

\section{Main results}

Significant variations were observed in the monthly distribution of ACS, with the highest value in April $(n=168)$ and the lowest in July $(n=20)(p=0.001)$ (Fig 3$)$. The CPR was 53.42 per $100000 \mathrm{inh}$. The CPR varied from 4.60 to 74.25 and to 175.54 per 100000 inh among patients aged less than 40 years, 40-60 years old and over 60 years, respectively $(p<0.001)$. The SPR was $69.97 / 100$ $000 \mathrm{PY}$ and was higher in men $(96.24 / 100000 \mathrm{PT})$ than in women $(43.70 / 100000 \mathrm{PY})(p<0.001)$ (Table 3$)$.

\section{Distribution of CVRFs and relationship with ACS}

Hypertension, active smoking and type 2 diabetes were the most reported modifiable CVRFs among patients with ACS (53\%). In the multivariable analysis, CVRFs related to STEMI were age correlated to gender (OR:2.55 [95\% CI: 1.61-4.06]) and active smoking (OR 2.51 [95\% CI:1. 36 - 3.84]). The CVRFs related to UA/NSTEMI were age correlated to gender (OR: 1.47 [95\% CI 1.07-2.02]), coronary personal history (OR 2.55 [95\% CI $1.79-3.64$ ]) and type 2 diabetes (OR 2.34 [95\% CI 1.67 -3.28]) (Table 4). A significant and high linear relation was established between the number of CVRFs and the risk of developing ACS $(r=0.92 ; \mathrm{b}=0.62 ; p<0.0001)$, especially with UA/NSTEMI $(\mathrm{r}=0.96 ; \mathrm{b}=0.795 ; p<0.0001)$. The odds ratio of developing UA/NSTEMI was equal to the number of CVRFs +1 (Fig 4). 


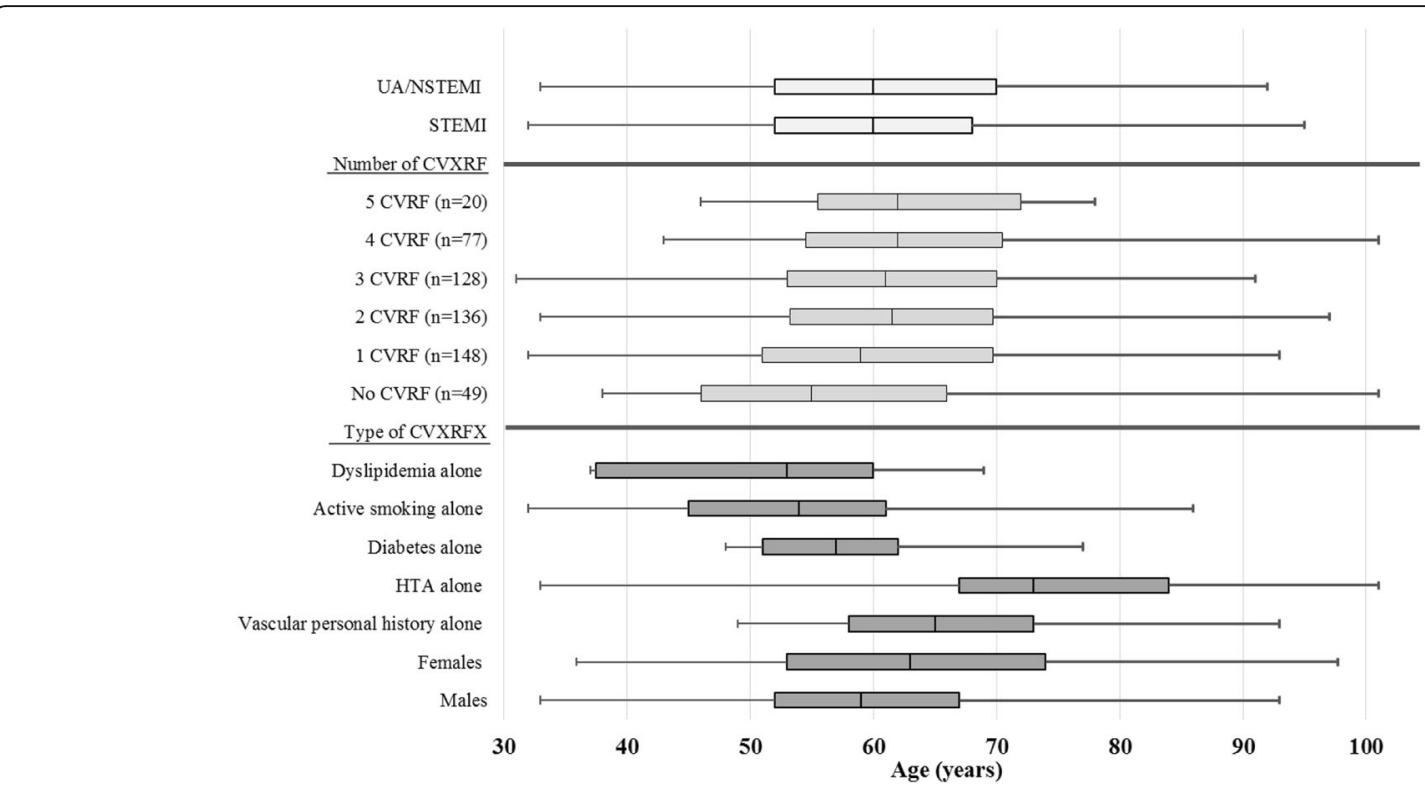

Fig. 1 Age distribution by ACS and CardioVascular Risk Factors (CVRFs) subgroups (quartile range (years)). Legend: The median age was equal among patient having STEMI and UA/NSTEMI (60 years (IQR 52-68) and 60 years (IQR 52-70), respectively); it was 55 years (IQR 46-66) among patients with no CVRFs and 62 years in those having five CVRFs

\section{Discussion \\ Key results}

We reported that ACS occurred among half of the patients presenting for chest pain in emergency departments in Tunisia. The management of ACS was weak, and the duration between chest pain onset and ED arrival was longer than in developed countries. According to age-standardized prevalence rates, the ACS prevalence was significantly lower than in developed countries. Male predominance is universal. By logistic binary regression, cardiovascular risk factors related to ACS, adjusted for age and gender, were smoking for ACS with STEMI and diabetes and coronary personal history for ACS with UA/ NSTEMI. By linear regression, we established a significant and strong relationship between the number of associated cardiovascular risk factors and estimated odds ratios, especially for ASC with UA/NSTEMI. MACE occurred more frequently among STEMI patients.
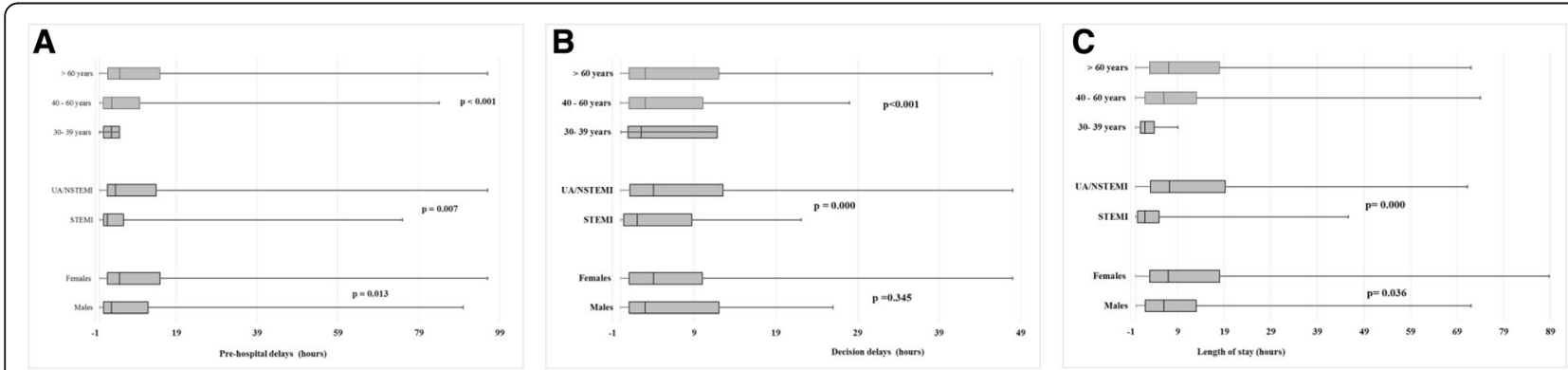

Fig. 2 Delays of ACS management in Emergency Departments (EDs) (Tunisia). a The median duration between chest pain onset and EDs arrival was $2 \mathrm{~h}(\mathrm{IQR} 2-4 \mathrm{~h})$ for men and $3 \mathrm{~h}(\mathrm{IQR} 2-4 \mathrm{~h})$ for women $(p=0.013)$. This median duration was higher for the elderly [3 h (IQR:2-4 h)] than for younger patients [2 h (IQR:2-4 h)] ( $p=0.007)$ and among patients with UA/NSTEMI [2 h (IQR 1-4 h)] compared to STEMI [2 h (IQR1-3 h)] ( $p<0.001)$. b The median decision time (duration between ED admission and starting treatment) was $4 \mathrm{~h}$ (IQR: $2-8 \mathrm{~h}$ ) for all subgroups, for men and women $(p=0.230)$. This duration increased with age to $3 \mathrm{~h}$ (IQR 2-5h) for 30 - 39-year olds, 4 hours (IQR 2-8 h) for 40 - 60-year olds, and $4 \mathrm{~h}$ (IQR 2-10 h) for the elderly $(p<0.001)$. The median decision time was $2 \mathrm{~h}$ (IQR 0:10-8:30 $\mathrm{h}$ ) for STEMI and $4 \mathrm{~h}($ IQR 1:00-12:30 $\mathrm{h})$ for UA/NSTEMI patients. c The median ED length of stay (LOS) was 1 hour (IQR 0-1) for regional hospitals and 8 hours (h) (IQR 4-18 h) for university EDs ( $p<0.001$ ). The LOS in the ED was higher among woman (7 h; IQR: 3- 18 h) than men (6 h; IQR 2-13 h) ( $p=0.036)$. The LOS increased significantly with increasing age; it was 4 hours (IQR: 2-9 h) for patients aged 30-39 years, 6 hours (IQR 2-13 h) for the 40 - 60 years group, and increased to 7 hours (IQR3-18 h) for patients over 60 years $(p<0.001)$. Patients with STEMl had a short median LOS (2 h; $(0-5 \mathrm{~h})$ compared to those with UANNSTEMI [8 h (IQR: 4-20 h)] (p<0.001) 
Table 2 Acute coronary syndrome management according to all ACS, STEMI or UA/NSTEMI

\begin{tabular}{|c|c|c|c|c|}
\hline & All ACS $(n=566)$ & STEMI $(n=146)$ & UA/NSTEMI $(n=420)$ & $p$ \\
\hline Duration between chest pain onset and ED arrival : median (IQR) (hour) & $2(1-4)$ & $2(1-3)$ & $2(1-4)$ & 0.000 \\
\hline Duration between ED admission and treatment starting: median (IQR) (hour) & $3(1-11)$ & $2(0.33-8.7)$ & $4(1.12-12.5)$ & 0.000 \\
\hline ED length of stay: median (IQR) & $6(2.75-16)$ & $2(0.5-5)$ & $8(4-20)$ & 0.000 \\
\hline \multicolumn{5}{|l|}{ Medications } \\
\hline$\beta$ blockers & $66(14.6)$ & $4(3.6)$ & $62(18.1)$ & 0.000 \\
\hline Converting enzyme inhibitors & $82(18.3)$ & $11(9.9)$ & $71(21.0)$ & 0.009 \\
\hline \multicolumn{5}{|l|}{ In hospital management of ACS } \\
\hline Thrombolysis n (\%) & $41(7.2)^{*}$ & $37(25.3)^{* *}$ & $4(0.95)$ & 0.000 \\
\hline Streptokinase & 21 & 19 & 3 & \\
\hline Alteplase & 20 & 18 & 1 & \\
\hline \multicolumn{5}{|l|}{ Administered treatment: $n(\%)$} \\
\hline Aspirin & 499 (91.9) & $133(97.1)$ & $366(90.1)$ & 0.010 \\
\hline Clopidogrel & $392(74.1)$ & $124(89.9)$ & $268(68.5)$ & 0.000 \\
\hline LMWH (HNF) & $254(49.9)$ & $84(64.6)$ & $170(44.9)$ & 0.000 \\
\hline \multicolumn{5}{|l|}{ Outcomes } \\
\hline MACE & $63(11.1)$ & $27(20.0)$ & $36(9.1)$ & 0.001 \\
\hline Deaths & 7 & 3 & 4 & 0.27 \\
\hline Cardiogenic shock & 8 & 4 & 4 & 0.09 \\
\hline Acute Pulmonary Oedema & 43 & 15 & 28 & 0.11 \\
\hline Arrhythmia & 18 & 12 & 6 & 0.000 \\
\hline Others (conduction disorders) & 9 & 7 & 2 & 0.26 \\
\hline Transfer to Cardiology Intensive Care Unit & 269 & $108(73.9)$ & $161(38.3)$ & 0.000 \\
\hline
\end{tabular}

\section{Limitations}

Several limitations should be considered. Due to the short study duration, the results must be interpreted with caution. It is worth further evaluation of outcomes with a longer follow-up. The private sector dealing with ACS patients was not included, and some patients with other form of ACS (silent MI) were not diagnosed. Therefore, these findings underestimated ACS in the whole Tunisian population.

\section{Interpretation}

Prospective national studies on the epidemiology of ACS are not as frequently reported in developing countries as in Tunisia. In this multicenter study that included fourteen regional and university hospitals, we enrolled 1173 patients consulting the ED for ACP. ACS prevalence, management and relation with CVRFs have rarely been described in our country [11-13]; it was considered necessary to conduct this study to provide the basis for adapted public health strategies and decisions.
The prevalence of ACS was similar to that described by Baccouche et al. [9] in a monocentric study performed in the Monastir ED three years ago. This relatively low Tunisian ACS prevalence can be explained by lifestyle differences and local habits [14]. The UA/ NSTEMI predominance in our study was similar to that described by Dilip et al. [15] and El-Menyar et al. [16] and different than the results of Bacci [17]. Gender and age distribution correlated with ACS are widely described in the literature $[18,19]$. We have observed that the median age of ACS was 54 years among smokers and 73 years among patients treated for hypertension. Our results were in agreement with those of Dilip et al. [15]. Due to the increased rate of cardiac events in smokers, further efforts for smoking cessation must be performed. The duration between chest pain onset and ED arrival and starting treatment were higher than those described by Mark et al. [20]. These times varied according to gender, age groups and ACS type. Appropriate identification of patients with symptoms of chest pain and early discharge as recommendations should be improved 


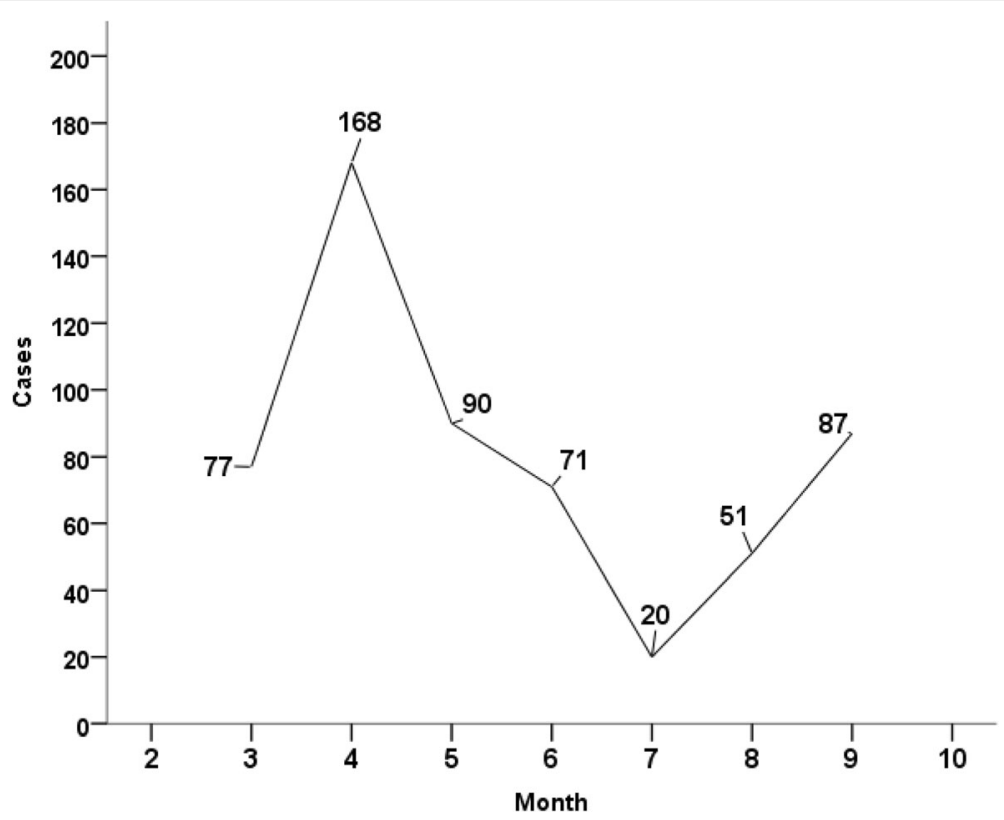

Fig. 3 Monthly distribution of acute coronary syndrome (Tunisia, 2015). Legend: Significant variations were observed in the monthly ACS distribution, with the highest in April $(n=168)$ and the lowest in July $(n=20)(p=0.001)$

[21-24]. We explained the increasing duration between chest pain onset and emergency arrival with increasing age by the emergence of social loneliness of the elderly in Tunisia $[11,14]$. The increasing length of stay in ED with increasing age, was explained by Jin $\mathrm{H}$ et al. as related to low education level, co-morbidities, and the total number of discharge medications for elderly patients [25]. We observed a significantly longer duration between ED admission and treatment among patients diagnosed as UA/NSTEMI versus STEMI. Mark et al. established that these delay parameters were not influenced by sociodemographic characteristics, vascular family history or the

Table 3 Crude and age-standardized prevalence rates of acute coronary syndrome

\begin{tabular}{llcc}
\hline & CPR/100000 inh & r & ASR/100,000 PY \\
\hline All & 53.42 & & 69.97 \\
Gender & & \\
$\quad$ Male & 86.6 & & \\
$\quad$ Female & $38.62^{*}$ & 43.24 \\
Age groups & & & \\
$\quad<$ 40 years & 4.60 & $0.64^{*}$ & \\
40-60 years & 74.25 & & \\
$>$ 60 years & 175.54 & & \\
\hline
\end{tabular}

CPR Crude prevalence rate, $r$ Standardized coefficient, ASR Standardized prevalence rate, $P Y$ Person year

Missing value for age $(n=2) .^{*}: p<0.000$;

Legend: Prevalence rates were higher in men and population aged more than 60 years
ACS subgroup (STEMI or UA/NSTEMI); they considered that this duration is influenced by the knowledge of general practitioners and a better ambulance service [20]. Adherence to international guidelines, in our cohort, was largely less than that described by Gregory J. Dehmer et al. [26] in the United States and by Prashanth Panduranga in Oman [27]. The SPR was $69.97 / 100000$ inh in our study, which is lower than the rates reported in developed and rich countries [28-31] and in Arabian Gulf countries, in which Al-Lawatiet et al. described a rate of 779 and 674 per 100,000 PY for men and women, respectively, in 2007 [29]. The variability between countries might be explained by several factors such as socio-demographic conditions, population education levels, health politics implications and, especially, nutritional habits. We have gathered literature evidence of a predominance of men [18]. Women presenting with ACS are older than men regardless of the increasing risk with increasing age in the two genders [32]. We have determined that the risk of ACS is highly correlated to the number of conventional risk factors. Eighteen percent of our patients with ACS had at least one conventional risk factor. In our study, active smoking was the most modifiable CVRF observed (55.5\%) among STEMI cases and is directly associated to ACS, especially to STEMI; similar results were observed by El-Menyar et al. [16]. Smoking was also found to be a high risk factor by Kastorini et al. and Notara et al. $[33,34]$. Diabetes mellitus was the most modifiable CVRF present (52.4\%) among UA/NSTEMI cases. Diabetes was associated with all ACS and to UA/NSTEMI. 
Table 4 Distribution of conventional cardiovascular risk factors according to all ACS, by STEMI or UA/ NSTEMI

\begin{tabular}{|c|c|c|c|c|c|c|}
\hline \multirow[b]{2}{*}{ Variables } & \multicolumn{2}{|c|}{$\operatorname{ALL} \operatorname{ACS}(n=566)$} & \multicolumn{2}{|c|}{ STEMI $(n=146)$} & \multicolumn{2}{|c|}{ UA/NSTEMI $(n=420)$} \\
\hline & $\mathrm{N}(\%)$ & $\mathrm{OR}^{*}[\mathrm{Cl} 95 \%]$ & $\mathrm{N}(\%)$ & $\mathrm{OR}^{* *}[\mathrm{C} 195 \%]$ & $\mathrm{N}(\%)$ & $\mathrm{OR}^{* * *}[\mathrm{Cl} 95 \%]$ \\
\hline \multicolumn{7}{|l|}{ Cardiovascular risk factors type } \\
\hline Not modifiable CVRF & & & 146 & & 420 & \\
\hline A/Age correlated with gender & $336(59.4)$ & $1.71[1.29-2.27]^{d}$ & $90(61.6)$ & $2.55[1.61-4.06]^{d}$ & $243(57.9)$ & $1.47[1.07-2.02]^{\mathrm{e}}$ \\
\hline BNascular personal history & $255(45.1)$ & & $35(24.0)$ & & $210(50.0)^{a}$ & \\
\hline Coronary personal history & $210(37.1)$ & $1.87[1.34-2.59]^{\mathrm{d}}$ & $24(16.4)$ & $0.64[0.36-1.14]$ & $184(43.8)^{a}$ & $2.55[1.79-3.64]^{d}$ \\
\hline Peripheral arterial history & $38(6.7)$ & & $6(04.1)$ & & $31(7.4)$ & \\
\hline Stroke & $50(8.8)$ & & $9(06.2)$ & & $40(09.5)$ & \\
\hline Revascularization & $145(25.6)$ & & $13(08.9)$ & & $131(31.2)^{\mathrm{a}}$ & \\
\hline \multicolumn{7}{|l|}{ Modifiable and direct CVRF } \\
\hline $\mathrm{C} /$ Treated HTA & $300(53.0)$ & $1.23[0.91-1.68]$ & $65(44.5)$ & $1.08[0.66-1.75]$ & $232(41.8)$ & $1.26[0.90-1.75]$ \\
\hline D/Treated Diabetes type 2 & $248(43.8)$ & $2.04[1.49-2.80]^{\mathrm{d}}$ & $51(34.9)$ & $1.30[0.76-2.21]$ & $195(52.4)^{b}$ & $2.34[1.67-3.28]^{d}$ \\
\hline E/Active smoking & $262(46.3)$ & $1.50[1.14-2.00]^{\mathrm{e}}$ & $81(55.5)$ & $2.51[1.63-3.84]^{\mathrm{d}}$ & $178(36.6)^{b}$ & $1.18[0.86-1.60]$ \\
\hline F/Treated Dyslipidemia & $162(28.6)$ & $0.81[0.57-1.15]$ & $29(19.9)$ & $0.77[0.43-1.37]$ & $132(44.1)^{\mathrm{b}}$ & $0.78[0.53-1.14]$ \\
\hline \multicolumn{7}{|l|}{ Modifiable and indirect CVRF } \\
\hline G/ Obesity & $147(26.0)$ & $1.18[0.84-1.65]$ & $34(23.3)$ & $1.02[0.58-1.73]$ & 111 (39.6) & $1.21[0.84-1.74]$ \\
\hline Patients treated by CEI & $192(33.9)$ & $0.72[0.53-0.97]^{d}$ & $35(24.0)$ & $0.56[0.33-0.93]^{d}$ & $157(37.4)^{a}$ & $0.77[0.52-1.14]$ \\
\hline \multicolumn{7}{|l|}{ Sum of CVRF } \\
\hline 0 & $39(6.9)$ & 1,00 & $10(6.8)$ & 1,00 & $29(06.9)$ & 1,00 \\
\hline 1 & $105(18.6)$ & $2,36[1.52-3.67]^{d}$ & $34(23.3)$ & $3,24[1.55-6.79]^{\mathrm{d}}$ & $68(16.2)$ & $2,05[1.25-3.38]^{\mathrm{d}}$ \\
\hline 2 & $130(23.0)$ & $3,28[2.12-5.08]^{d}$ & $37(25.3)$ & $3,64[1.73-7.65]^{d}$ & $93(22.1)$ & $3,15[1.94-5.13]^{d}$ \\
\hline 3 & $119(21.0)$ & $3,59[2.29-5.62]^{d}$ & $31(21.2)$ & $3,65[1.71-7.80]^{d}$ & $88(21.0)$ & $3,57[2.17-5.86]^{d}$ \\
\hline 4 & $96(17.0)$ & $4,48[2.77-7.22]^{d}$ & $16(11.0)$ & $2,91[1.25-6.77]^{f}$ & $80(19.0)$ & $5,02[2.98-8.44]^{d}$ \\
\hline 5 & $49(08.7)$ & $4,57[2.58-8.08]^{\mathrm{d}}$ & $10(06.8)$ & $3,64[1.39-9.47]^{\mathrm{e}}$ & $39(09.3)$ & $4,89[2.64-9.05]^{d}$ \\
\hline 6 & $19(03.4)$ & $4,50[2.04-9.93]^{d}$ & $3(02.1)$ & $2,77[0.67-11.36]$ & $16(03.8)$ & $5,09[2.21-11.76]^{d}$ \\
\hline 7 & $6(01.1)$ & $9,23[1.79-47.61]^{e}$ & $2(01.4)$ & & $4(01.0)^{a}$ & $8,28[1.45-47.39]^{f}$ \\
\hline
\end{tabular}

Chi 2 pearson test (STEMI vs UA/NSTEMI): ${ }^{\mathrm{a}} p$ value $<10^{-3} ;{ }^{\mathrm{b}}: p$ value $<0.005$

Binary logistic analysis*: All SCA vs All chest pain; **All STEMI vs All chest pain: ***: All UA/NSTEMI. vs All chest pain; ${ }^{d}: p$ value $<0.001 ;{ }^{\text {e }}: p$ value $<0.005 ;{ }^{f}: p$ value $<0.05$ ACS Acute coronary syndrome, UA/NSTEMI unstable angina/non-ST-segment-elevation myocardial infarction, CVRF cardiovascular risk factors, STEMI ST segment elevation myocardial infarction, OR Odds Ratio, HTA Hypertension, CEI converting enzyme inhibitors

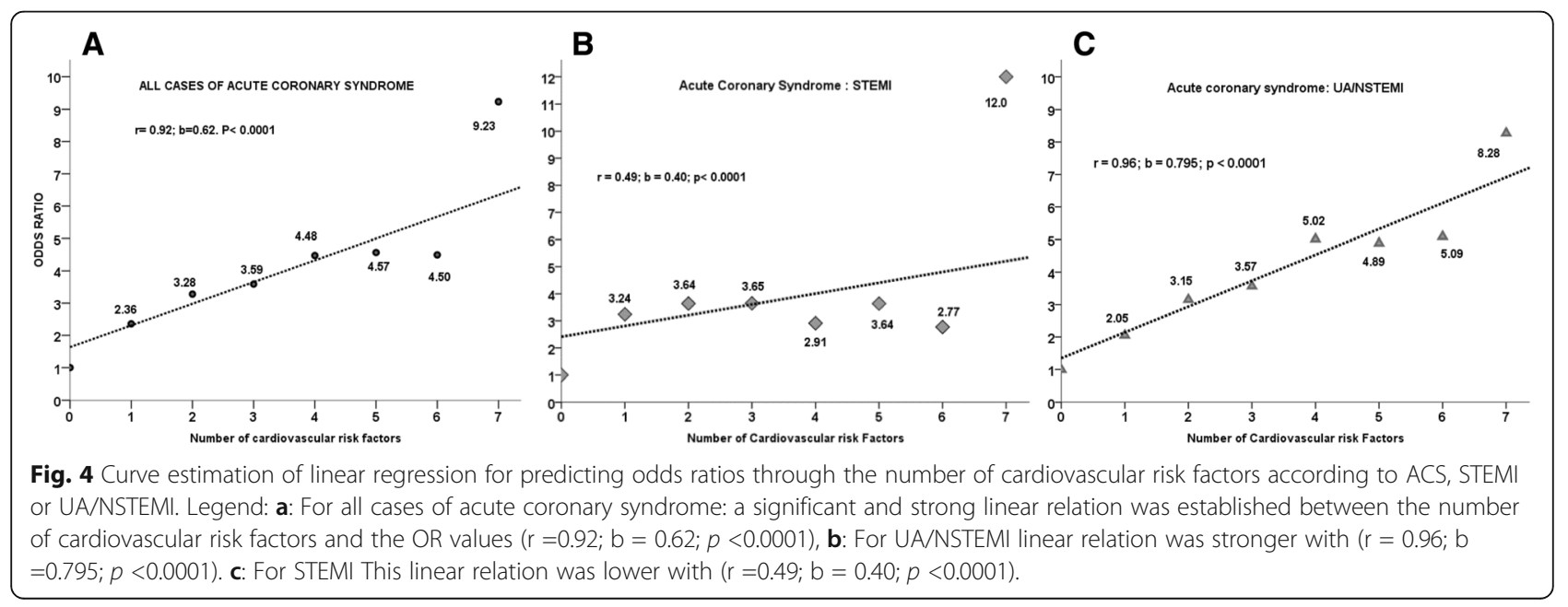


Our results are consistent with literature data $[15,35,36]$. Ahmadi et al. concluded that patients with metabolic syndrome have a significantly greater prevalence, severity, and prognosis of coronary artery disease [37]. Chalghoum et al. observed a metabolic relationship between endothelin-1 and ACE inhibitors among Tunisians with a coronary personal history [38]. Singh et al. reported a significant association between ACE inhibitors and decreased in-hospital remyocardial infarction risk.

\section{Generalizability}

The implementation of an ACS register will give us a method for monitoring prevalence trends and management, providing important information for health policy decisions. Moreover, there is a need to increase adherence to international guidelines to improve patient outcomes. These findings should be confirmed by other national registries.

\section{Conclusions}

Our results showed a high prevalence of ACS in a Tunisian population presenting to the emergency department for acute chest pain, with a close relation with CVRFs. Efforts for a public awareness campaign and training program for ED physicians that have improved ACS management in Tunisian EDs should be maintained and expanded.

\section{Abbreviations}

ACE inhibitors: converting enzyme inhibitors; ACS: Acute coronary syndrome; ASR: Age-standardized prevalence rate; CPRs: Crude prevalence rates; CVRFs: Cardiovascular risk factors; EDs: Emergency departments; Inh: Inhabitants; MACE: Major adverse cardiac events; OAD: Oral antidiabetics: STEMI: ST segment elevation myocardial infarction; UA/NSTEMI: Unstable angina/non-ST-segment- elevation myocardial infarction

\section{Acknowledgements}

We thank the ESCorT team (Krid Jamel, Chtara Majed, Nouira Semir Marghelli Soudani, Slim Anis, Gassab Khaled, Ben Amor Mehdi, Boukef Riadh, Methammem Mehdi, Aissa Jalled Ahlem, Bouhamed Chafiaa, Borsali Falfoul N, Ben Cheikh Maamoun, Souissi Mohamed Hedi, and Souissi Sami).

\section{Funding}

This study was carried out with the financial support of Sanofi (by helping NS to initiate the Registry named: "ESCorT" (Registry number: DIREGL07283) and to provide necessary resources

\section{Availability of data and materials}

Further publications are planned using this dataset. Therefore, anonymized participant-level data are available on reasonable request by email to the corresponding author

\section{Authors' contributions}

The ESCorT Investigators group participated in the data collection, and HM wrote the protocol. ASB HA, BF M and ZI drafted this manuscript and performed the statistical analyses and interpretation of the findings. The statistical analyses were confirmed by BK, MMA, BW, GMH, and $\mathrm{BH}$. NS contributed to the preparation of the manuscript and approved the final manuscript. All authors read and approved the final manuscript.

\section{Ethics approval and consent to participate}

This study was conducted in accordance with the principles laid down by the 18th World Medical Assembly (Helsinki, 1964) including all subsequent amendments. (The ethics committee of the university hospital of Monastir approved this study in 2014). Physicians informed patients about the study objectives and design, and then they obtained signed informed consent. The patient's legal representative could also sign the written informed consent form on behalf of the patient. A copy of the signed consent was provided to the patient or to his legal representative.

\section{Consent for publication}

Not applicable.

\section{Competing interests}

The authors declare that they have no competing interests (Hotels and lunch) for the meetings between the members of the team who collected the data in several centers of the country.

\section{Publisher's Note}

Springer Nature remains neutral with regard to jurisdictional claims in published maps and institutional affiliations.

\section{Author details}

${ }^{1}$ Epidemiology and Preventive Medicine Department, University Hospital of Monastir, Monastir, Tunisia. ${ }^{2}$ Research Laboratory (LR12SP18), University of Monastir, Monastir, Tunisia. ${ }^{3}$ National Institute of Public Health, Tunis, Tunisia.

Received: 10 October 2018 Accepted: 15 November 2018

Published online: 03 December 2018

\section{References}

1. $\mathrm{WHO} \mid$ Cardiovascular diseases (CVDs). WHO. 2017. Available from: $h$ file:/// C:/Users/Asus/Downloads/9789241564373_eng\%20(2).pdf.

2. O'Connor RE, Brady W, Brooks SC, Diercks D, Egan J, Ghaemmaghami C, et al. Part 10: acute coronary syndromes: 2010 American Heart Association Guidelines for Cardiopulmonary Resuscitation and Emergency Cardiovascular Care. Circulation. 2010;122:S787-817.

3. Niccoli G, Scalone G, Crea F. Acute myocardial infarction with no obstructive coronary atherosclerosis: mechanisms and management. Eur Heart J. 2015:36:475-81.

4. Anderson JL, Adams CD, Antman EM, Bridges CR, Califf RM, Casey DE Jr, et al. 2012 ACCF/AHA focused update incorporated into the ACCF/AHA 2007 guidelines for the management of patients with unstable angina/non-STelevation myocardial infarction: a report of the American College of Cardiology Foundation/American Heart Association Task Force on Practice Guidelines. J Am CollCardiol. 2013;61:e179-347.

5. Hamm CW, Bassand JP, Agewall S, Bax J, Boersma E, Bueno H, et al. ESC Guidelines for the management of acute coronary syndromes in patients presenting without persistent ST-segment elevation: The Task Force for the management of acute coronary syndromes (ACS) in patients presenting without persistent ST-segment elevation of the European Society of Cardiology (ESC). Eur Heart J. 2011;32:2999-3054.

6. Kushner FG, Hand M, Smith SC Jr, King SB 3rd, Anderson JL, Antman EM, et al. 2009 focused updates: ACC/AHA guidelines for the management of patients with ST-elevation myocardial infarction (updating the 2004 guideline and 2007 focused update) and ACC/AHA/ACSI guidelines on percutaneous coronary intervention (updating the 2005 guideline and 2007 focused update) a report of the American College of Cardiology Foundation/American Heart Association Task Force on Practice Guidelines. J Am CollCardiol. 2009;54:2205-41.

7. Steg PG, James SK, Atar D, Badano LP, Blomstrom-Lundqvist C, Borger MA, et al. ESC Guidelines for the management of acute myocardial infarction in patients presenting with ST-segment elevation. EurHeart J. 2013;33:2569-619.

8. Lapostolle F, Bataille S, Tafflet M, Dupas F, Laborne F, Mouranche X, et al. Evolution since 2002 of the management of patients with ST elevated acute coronary syndrome (STEMI) in Ile-de- France. E-MUST survey. Presse Med. 2015:44:e273-81.

9. Baccouche $H$, Belguith AS, Boubaker H, Grissa MH, Bouida W, Beltaief K, et al. Acute coronary syndrome among patients with chest pain: Prevalence, incidence and risk factors. Int J Cardiol. 2016;214:531-5. 
10. Statistiques Tunisie. Recensement Tunisian National Institute of Statistics Available at: http://www.ins.nat.tn. Accessed 4 June 2017.

11. Ekelund U, Akbarzadeh M, Khoshnood A, Bjork J, Ohlsson M. Likelihood of acute coronary syndrome in emergency department chest pain patients varies with time of presentation. BMC Res Notes. 2012;08(5):420.

12. Dracup K, McKinley S, Riegel B, Moser DK, Meischke H, Doering LV, et al. A randomized clinical trial to reduce patient prehospital delay to treatment in acute coronary syndrome. CircCardiovascQual Outcomes. 2009;2:524-32.

13. Wibring K, Herlitz J, Christensson L, Lingman M, Bang A. Prehospital factors associated with an acute life-threatening condition in non-traumatic chest pain patients - A systematic review. Int J Cardiol. 2016;219:373-9.

14. Demirkan B, Ege MR, Dogan P, Ipek EG, Guray U, Guray Y. Factors influencing the use of ambulance among patients with acute coronary syndrome: results of two centers in Turkey. Anadolu Kardiyol Derg. 2013;13:516-22

15. Dilip C, Cholamugath S, Baby M, Pattani D. Prevalence of cardiovascular risk factors and management practices of acute coronary syndrome in a tertiary care hospital. J Basic Clin Physiol Pharmacol. 2015;26:547-54.

16. El-Menyar A, Zubaid M, Shehab A, Bulbanat B, Albustani N, Alenezi F, et al. Prevalence and impact of cardiovascular risk factors among patients presenting with acute coronary syndrome in the middle East. Clin Cardiol. 2012;34:51-8.

17. Bacci MR, Fonseca FL, Nogueira LF, Bruniera FR, Ferreira FM, Barros DM, et al. Predominance of STEMI and severity of coronary artery disease in a cohort of patients hospitalized with acute coronary syndrome: a report from ABC Medical School. Rev Assoc Med Bras. 1992;2015(61):240-3.

18. Kawamoto KR, Davis MB, Duvernoy CS. Acute Coronary Syndromes: Differences in Men and Women. Curr Atheroscler Rep. 2016;18:73.

19. Pelletier R, Khan NA, Cox J, Daskalopoulou SS, Eisenberg MJ, Bacon SL, et al. Sex Versus Gender-Related Characteristics: Which Predicts Outcome After Acute Coronary Syndrome in the Young? J Am CollCardiol. 2017;67:127-35.

20. Mark L, Dani G, Vendrey R, Ruzsa J, Katona A. Improvement in prehospital time in acute coronary syndrome between 1985 and 2013 in the southeastern area of Hungary. Wien KlinWochenschr. 2015;127:218-21.

21. Engel J, Poldervaart JM, van der Wulp I, Reitsma JB, de Bruijne MC, Bunge JJ, et al. Selecting patients with non-ST-elevation acute coronary syndrome for coronary angiography: a nationwide clinical vignette study in the Netherlands. BMJ Open. 2017;7:e011213.

22. Hillinger $P$, Twerenbold $R$, Wildi $K$, RubiniGimenez $M$, Jaeger $C$, Boeddinghaus J, et al. Gender-specific uncertainties in the diagnosis of acute coronary syndrome. Clin Res Cardiol. 2016;106:28-37.

23. Nestler DM, Gilani WI, Anderson RT, Bellolio MF, Branda ME, LeBlanc A, et al. Does gender bias in cardiac stress testing still exist? A videographic analysis nested in a randomized controlled trial. Am J Emerg Med. 2017:35:29-35.

24. Sepehrvand N, Zheng Y, Armstrong PW, Welsh RC, Ezekowitz JA. Identifying Low-risk Patients for Early Discharge From Emergency Department Without Using Subjective Descriptions of Chest Pain: Insights From Providing Rapid Out of Hospital Acute Cardiovascular Treatment (PROACT) 3 and 4 Trials. AcadEmerg Med. 2017;24:691-700.

25. Jin H, Tang C, Wei Q, Chen L, Sun Q, Ma G, et al. Age-related differences in factors associated with the underuse of recommended medications in acute coronary syndrome patients at least one year after hospital discharge. BMC CardiovascDisord. 2014;14:127.

26. Gregory J, Dehmer DW, Matthew T. Roe, Sarah Milford-Beland, Susan Fitzgerald, Anthony Hermann et al A Contemporary View of Diagnostic Cardiac Catheterization and Percutaneous Coronary Intervention in the United States. JACC. 2012;60:2017-31.

27. Panduranga P, Al-Rashidi M, Al-Hajri F. In-Hospital and One-Year Clinical Outcome of Percutaneous Coronary Intervention in a Tertiary Hospital in Oman: Oman PCI Registry. Oman Med J. 2017;32:54-61.

28. Blais $C$, Rochette $L$. Trends in prevalence, incidence and mortality of diagnosed and silent coronary heart disease in Quebec. Health Promot Chronic Dis Prev Can. 2015;35:184-93.

29. Al-Lawati J, Sulaiman K, Panduranga P. The Epidemiology of Acute Coronary Syndrome in Oman: Results from the Oman-RACE study. Sultan QaboosUniv Med J. 2013;13:43-50.

30. Nielsen KM, Foldspang A, Larsen ML, Gerdes LU, Rasmussen S, Faergeman O. Estimating the incidence of the acute coronary syndrome: data from a Danish cohort of 138290 persons. Eur J Cardiovasc Prev Rehabil. 2007:14:608-14.
31. Pitsavos C, Panagiotakos DB, Antonoulas A, Zombolos S, Kogias Y, Mantas Y, et al. Epidemiology of acute coronary syndromes in a Mediterranean country; aims, design and baseline characteristics of the Greek study of acute coronary syndromes (GREECS). BMC Public Health. 2005;5:23.

32. Khan NA, Daskalopoulou SS, Karp I, Eisenberg MJ, Pelletier R, Tsadok MA, et al. Sex differences in prodromal symptoms in acute coronary syndrome in patients aged 55 years or younger. Heart. 2016;103:863-9.

33. Kastorini CM, Georgousopoulou E, Vemmos KN, Nikolaou V, Kantas D, Milionis $\mathrm{HJ}$, et al. Comparative analysis of cardiovascular disease risk factors influencing nonfatal acute coronary syndrome and ischemic stroke. Am J Cardiol. 2013;112:349-54.

34. Notara V, Panagiotakos DB, Kouroupi S, Stergiouli I, Kogias Y, Stravopodis P, et al. Smoking determines the 10-year (2004-2014) prognosis in patients with Acute Coronary Syndrome: the GREECS observational study. Toblnduc Dis. 2015;13:38.

35. Cziraky MJ, Reddy VS, Luthra R, Xu Y, Wilhelm K, Power TP, et al. Clinical outcomes and medication adherence in acute coronary syndrome patients with and without type 2 diabetes mellitus: a longitudinal analysis 2006-2011. J Manag Care Spec Pharm. 2015;21:470-7.

36. Esteghamati A, Abbasi M, Nakhjavani M, Yousefizadeh A, Basa AP, Afshar H. Prevalence of diabetes and other cardiovascular risk factors in an Iranian population with acute coronary syndrome. CardiovascDiabetol. 2006:5:15.

37. Ahmadi A, Leipsic J, Feuchtner G, Gransar H, Kalra D, Heo R, et al. Is metabolic syndrome predictive of prevalence, extent, and risk of coronary artery disease beyond its components? Results from the multinational coronary CT angiography evaluation for clinical outcome: an international multicenter registry. PLoSOne. 2015;3;10:e0118998.

38. Chalghoum ANY, Dandana A, Baudin B, Miled A, Ferchichi S. Pathological interactions between the endothelin-1 and the angiotensin- converting enzyme among Tunisian coronary patients. BMC Cardiovasc Disord. 2016; 16(1):244 PubMed PMID: 27894250; PubMed Central PMCID: PMC5127035.
Ready to submit your research? Choose BMC and benefit from:
- fast, convenient online submission
- thorough peer review by experienced researchers in your field
- rapid publication on acceptance
- support for research data, including large and complex data types
- gold Open Access which fosters wider collaboration and increased citations
- maximum visibility for your research: over $100 \mathrm{M}$ website views per year
At BMC, research is always in progress.
Learn more biomedcentral.com/submissions 